\title{
RED CELL AND PLASMA VOLUME IN NEWBORN INFANTS
}

\author{
BY \\ P. L. MOLLISON, N. VEALL, and MARIE CUTBUSH \\ From the Medical Research Council's Blood Transfusion Research Unit and Radiotherapeutic \\ Research Unit, Postgraduate Medical School of London
}

(Received for Publication March 6, 1950)

Schücking (1879) estimated the total blood volume of six newborn infants. In two infants, whose cords had been tied soon after delivery, blood volume was distinctly smaller than in four other infants whose cords had not been tied until some minutes after delivery. However, these estimates were made by Welcker's method and were by no means exact. The plasma volume of newborn infants was measured by Lucas and Dearing (1921) using brilliant vital red, with rather variable results. Robinow and Hamilton (1940), using the same method, found an inverse relationship between haematocrit and plasma volume, and noted that high blood volumes were slightly more common when the haematocrit was high. Estimations with the dye Evans blue were made by Brines, Gibson, and Kunkel (1941), and by Russell (1949), but both these studies were chiefly concerned with children rather than with very young infants.

A more extensive study of the plasma volume of newborn infants was made by DeMarsh, Windle, and Alt (1942), who were particularly concerned with demonstrating the effects on blood volume of early and late tying of the cord. Total blood volume was calculated from plasma volume and venous haematocrit. Their findings may be summarized as follows: in infants who were deprived of their placental blood by early clamping of the cord, the haematocrit did not rise after delivery; by contrast, in infants who recovered their placental blood, the venous haematocrit rose, on the average, from $51^{\circ}$ o to $61^{\circ}$, within three hours of birth. The plasma volume three hours after birth was not significantly greater in infants recovering their placental blood than in those deprived of it - further evidence of the rapidity of the adjustment. Three days after birth the findings were substantially the same, that is, the average plasma volume in the two groups was almost identical but the venous haematocrit averaged $60^{\circ} \%$ in those infants who had recovered their placental blood and was only $51 \%$ in those who had been deprived of it. There were considerable variations between individual estimates. For example, in one infant whose blood volume was estimated on the first and third days of life, the figure was $408 \mathrm{ml}$. on the first day and $243 \mathrm{ml}$. on the third day. That this difference in the estimates was largely to be ascribed to experimental error is suggested by the observation that the venous haematocrit was substantially the same on the two occasions. One is bound to conclude that the method of plasma volume estimation carried rather a large error.

Although the main conclusions of DeMarsh et al. on the effect of placental transfer appear to be soundly established, the figures for total blood volume published by them cannot be taken as a reliable guide to the true blood volume of newborn infants. It is now widely recognized that estimates of blood volume based on plasma volume and venous haematocrit are higher than the true values. Smith, Arnold, and Whipple (1921), who were perhaps the first to reach this conclusion, suggested that the discrepancy was due to the fact that the proportion of red cells was higher in large vessels than in the body as a whole.

Hahn, Balfour, Ross, Bale, and Whipple (1941), and Gibson, Peacock, Seligman, and Sack (1946) estimated red cell volume using red cells tagged with radioactive iron. They found that these direct estimates were always lower than those deduced from measurements of plasma volume and venous haematocrit. Gibson et al. concluded that the ratio

$$
\frac{\text { whole body haematocrit }}{\text { venous haematocrit }}
$$

was a constant, the term ' whole body haematocrit' being used to denote the relationship between the true red cell volume and the true total blood volume. Their conclusion was based on observations made on human subjects whose venous haematocrit ranged from $38 \cdot 5 \%$ to $48 \cdot 1^{\circ}$ o and on dogs whose 
haematocrits ranged from $31_{\%}^{\circ}$ to $62^{\circ}$ o (only two above $53^{\circ}$, o).

It is evident that if the relationship of - whole body haematocrit 'to observed venous haematocrit is in fact a constant, it should be possible to measure total blood volume accurately simply by estimating plasma volume and venous haematocrit and then multiplying the venous haematocrit by the appropriate constant so as to discover the true red cell volume. It is to be noted that Gibson, Aub, Evans, Peacock, Irvine, and Sack (1947) and Ross, Finch, Peacock, and Sammons (1947) have stated that true red cell volume can be deduced from plasma volume and venous haematocrit in a different way. First,

then

$$
\text { Blood volume } \begin{aligned}
\quad & \text { Plasma volume } \times \frac{100}{(100-H)} \\
\text { where } H & =\text { venous haematocrit. }
\end{aligned}
$$

Observed red cell volume $=$ (blood volume) - (plasma volume);

this observed red cell volume is then multiplied by the 'constant' $0 \cdot 85$, to obtain the true red cell volume. Below, it will be demonstrated that this method of calculation is open to criticism.

At first sight it might appear that the true blood volume of normal infants could be discovered simply by recalculating the figures of DeMarsh et al. However, there are several reasons why this method could not be relied on to give precise answers. First, DeMarsh et al. found great variations in plasma volume from one case to another, suggesting a rather large experimental error. Secondly, even if it were true that the relationship of whole body haematocrit to observed venous haematocrit were constant in infants, as in adults, it could not be assumed that the constant had the same value in the two groups. Moreover, it cannot be assumed that the relationship between whole body haematocrit and venous haematocrit, which has been shown to apply in adults and dogs when the venous haematocrit ranges between $31^{\circ}$ o and $53^{\circ}$ o (or even to $62^{\circ} \%$ ), will continue to apply when the haematocrit rises to higher levels. For instance, the venous haematocrit of newborn infants may exceed $70^{\circ}{ }_{0}$.

Thus it appeared that the best way to discover the true blood volume of infants was to measure plasma volume and red cell volume separately. By doing this, it was hoped not only to establish reliable figures for the blood volume of newborn infants, but also to determine the relationship between observed venous haematocrit and whole body haematocrit over a wide range. The study was closely linked with another piece of work proceeding simultaneously. This had as its object the determination of the rate of red cell exchange during replacement transfusions in infants affected with haemolytic disease of the newborn. Thus, although the majority of the infants tested were healthy, some were affected with haemolytic disease of the newborn.

\section{Methods}

Selection of Cases. Fifty-three newborn infants were tested: of these, 38 were healthy and 15 were affected with haemolytic disease of the newborn. However, seven of the latter infants were only mildly affected and had venous haematocrit values within the normal range.

Clinical Procedure. At the moment of birth a small sample of blood was taken from the umbilical cord, to be mixed with radioactive phosphorus as described below. In some cases the cord was tied immediately after birth and in others was not tied until the umbilical vein had almost collapsed: in these latter cases the taking of the sample was delayed so as to interfere as little as possible with the transfer of blood from the placenta to the infant.

Of the blood volume estimations, $70^{\circ}$ o were carried out within six hours of birth; only two of these estimates were made less than one and a half hours after birth. In the remaining $30 \%$ of cases the estimates were made when the infant was $6 \frac{1}{2}-24$ hours old. With careful aseptic precautions the umbilical cord was completely divided about $2 \mathrm{~cm}$. from the abdominal wall and a 19-gauge pure polythene catheter, sterilized by boiling, was passed up the umbilical vein for a distance of $5-7 \mathrm{~cm}$. After withdrawing about $1 \mathrm{ml}$. of blood to rinse the zatheter, a new dry syringe was attached and a sample of 8 to $10 \mathrm{ml}$. was withdrawn. Then, through the same needle and catheter $1 \mathrm{ml}$. of a suspension of the infant's own red cells, prepared as described below, was injected from a calibrated syringe. After the injection blood was drawn back from the infant into the syringe and re-injected, and this washing-in was repeated about six times. Evans blue, $1 \mathrm{ml}$. (containing approximately $1 \mathrm{mg}$. of dye) was now washed in from another calibrated syringe in the same way. (The same two 1-ml. "tuberculin ' syringes were used throughout.) The catheter was now withdrawn. Approximately eight minutes later a new catheter was inserted and then, between nine and thirteen minutes after the injection, a sample was withdrawn, noting the precise time that had elapsed. As before, the catheter was first rinsed by withdrawing $1 \mathrm{ml}$. of blood before the sample (approximately $10 \mathrm{ml}$.) was obtained. The cord was now tied and dressed in the usual way. The procedure did not upset the infants at all and was not followed by any untoward sequelae. As a rule, the infant was not given penicillin as a prophylactic measure, and no infections were observed. In all cases the umbilical stump healed normally.

In 17 of the earlier cases a slightly different procedure was followed. No sample of blood was taken before the injection of the tagged red cells and dye, but two samples were taken afterwards, at 10 and 20 minutes respectively. In these cases the concentration of dye in the plasma was determined by Morris`s chromatographic method (1944). A further difference in eight of these cases was that the dye and radiocative cells were injected in a larger volume of fluid (total $15 \mathrm{ml}$.). 
Measurement of Plasma Volume. Plasma volume was measured by two methods, (a) direct, and $(b)$ by extraction.

(a) Direct Method. The concentration of dye in the 10-minute plasma sample was measured in the photoelectric colorimeter, in cells with an optical thickness of $5 \mathrm{~mm}$., using pre-injection plasma as a blank. The filter used was a combination of Ilford filters 803 and 205.* This filter is highly selective and traces of haemolysis do not cause appreciable errors. Nevertheless, in the one or two instances in the present series where samples were slightly haemolysed, the samples were discarded.

Standards were prepared in two ways: first, at the time of each blood volume determination, $20 \mathrm{c} . \mathrm{mm}$. of the dye injection solution was pipetted into $3 \mathrm{ml}$. of the infant's pre-injection plasma (after using the latter as a blank in the colorimeter), to give a 1151 dilution of the injection solution. These standards varied from one another by as much as $4^{\circ} \mathrm{o}$. It was demonstrated that the variation was mainly due to the irregular way in which T-1824 adhered to the walls of the capillary pipette rather than to any difference between plasma samples. The average value of the standards showed no tendency to rise or fall during the period of the experiments. It was considered that a more precise estimate of the standard could be obtained by making dilutions of Evans blue in plasma on a larger scale. Accordingly dye was delivered from the syringe used for injection into a volumetric flask. Various dilutions (in serum and plasma) were made and a calibration curve was obtained. It was noted that the relation between dye concentration in plasma and the optical density of the sample was substantially linear over the rather small range of concentrations encountered in this series. Therefore, finally, a standard galvanometer reading was taken as corresponding to a plasma volume of $150 \mathrm{ml}$. and all calculations of plasma volume were based on this figure. In fact this figure differed by only $1 \%$ from the average reading of all the small-scale standards referred to above.

(b) Extraction Method. In some preliminary experiments dye was added to plasma and then eluted by Morris's chromatographic method (1944). The recovery of the dye was estimated and found, as claimed by Morris, to be virtually complete.

As a further check the plasma volume of a few infants (and adults) was measured by this method, and by the direct estimation of the dye in plasma; very satisfactory agreement was found. Accordingly, in a series of 17 infants the plasma volume was estimated by this method. The first 13 cases gave figures which seemed mutually consistent, but the next four results were much higher. In two of these latter cases the plasma volume was also estimated by a direct method and found to be some $20^{\circ} \mathrm{o}$ lower than the estimates of the chromatographic method. It seemed certain that dye was being lost in the extraction process, and this was soon confirmed by a more extensive series of experiments in vitro. In these experiments the recovery of the dye was often complete, but in an

\footnotetext{
* We are grateful to Professor E. J. King for suggesting the use of these filters.
}

appreciable proportion of cases the dye was not completely absorbed from the plasma when the samples were passed through the aluminium hydroxide column. The difficulty was not overcome by substituting many different samples of $\mathrm{Al}(\mathrm{OH})_{3}$, nor by adopting the modified procedure recommended by Hecht and Greenberg (1948): we did not, however, succeed in obtaining the brand of $\mathrm{Al}(\mathrm{OH})_{3}$ recommended by the latter workers. It had thus to be concluded that in our hands the results of the chromatographic method could not be considered consistently reliable.

In the cases in which dye concentration was measured by the chromatographic extraction method, standards were prepared in two ways: either by injecting dye into a known volume of plasma from the syringe used in the estimation and then putting $2 \mathrm{ml}$. aliquots through the extraction process; or by pipetting small quantities of dye into known volumes of "eluent $B$ '.

Dye Loss. It was recognized that by taking only one sample of plasma, 10 minutes after the injection of the dye, some error would be introduced because of variable losses of dye from the circulation in individual cases. Noble and Gregersen (1946) found that in adults estimates based on a single sample taken 10 minutes after injection nearly always gave values between $-2^{\circ}$ o and $-4^{\circ}$ of the 'true' values, that is to say, the values calculated from extrapolation of the disappearance curve after mixing was complete.

Data obtained from our red cell volume estimates showed that in newborn infants mixing of red cells is virtually complete within 10 minutes of the injection. It is possible that mixing of the plasma is a little slower since it is known that red cells circulate more rapidly than does plasma (Freis, Stanton, and Emerson, 1949). But it seems likely that mixing of the plasma is at least very nearly complete at 10 minutes. Estimates of the rate of dye loss in newborn infants were obtained in two different ways: firstly, in those infants from whom samples were taken 10 and 20 minutes after injection and in whom dye concentration was measured by the extraction method. In these cases dye concentration was on the average $3^{\circ}$ lower in the 20 -minute samples than in those taken at 10 minutes. Secondly, in other cases, two or three plasma samples were taken during the few hours following injection: the estimates were corrected for the effect of haemodilution if any significant changes in haematocrit occurred. From these experiments it was concluded that the rate of dye loss in newborn infants is of the order of $20^{\circ}$ o per hour, and is thus appreciably higher than in adults. Accordingly, it is probable that during the $\mathbf{1 0}$ minutes after injecting the dye into infants, there is a loss of some $3^{\circ}$ o to $4^{\circ} \mathrm{o}$ compared with $1^{\circ}$, to $2^{\circ}$ oloss in adults during a similar period. If plasma mixing is complete at the end of 10 minutes, in the newborn infant, as it is in the adult. estimates based on the dye concentration of the 10-minute sample will thus tend to be, say, $3^{\circ}$ o too high, but any extra slowness in mixing in the newborn infant would cause an error in the opposite direction. Since it was not feasible to make direct measurements to estimate the mixing time in newborn infants, and since it appeared that in any case the correction involved would be a 
small one, it was decided to make no correction and to base all estimates of plasma volume on the dye concentration of the sample taken 10 minutes after injection.

One further point to consider is the possibility that after withdrawing such a relatively large amount of blood as $10 \mathrm{ml}$. from an infant, some haemodilution may occur, even during the subsequent 10 minutes. If this did occur, it would obviously introduce a further error into the calculation. However, the average change in venous haematocrit 10 minutes after withdrawing $10 \mathrm{ml}$. of blood, in 21 infants in whom observations were available, was found to be only -0.3 division on the haematocrit scale. At first sight this might appear to be evidence of slight haemodilution, but it must be remembered that when a venous blood sample is taken the blood removed is not strictly representative of the blood in the whole body but contains a higher proportion of red cells. Thus, even if there is no increase in plasma volume after withdrawing a blood sample, there will be a small fall in venous haematocrit as soon as the adjustment is complete. The extent of the fall expected in this particular series was calculated, using data described below, and was found to be 0.3 on the haematocrit scale. It was thus concluded that the very small fall in venous haematocrit observed was not evidence of any significant replacement of plasma following the withdrawal of the $10 \mathrm{ml}$. sample. The plasma volume before taking the first blood sample was calculated by estimating the plasma volume 10 minutes after injection and adding to this figure the amount of plasma removed in the first blood sample.

In eight of the cases in which plasma volume was estimated by the extraction method for Evans blue, the dye and radioactive cells were injected in a volume of approximately $15 \mathrm{ml}$. In estimating the pre-injection volume in these cases, a correction was applied on the assumption that the fluid was retained in the circulation during the 10 minutes after injection. Evidently this may have added to the error of these estimates, and it should be made clear that the main conclusions of this paper do not depend on this series of estimates. Plasma volume was estimated by the direct method in a further 25 infants, and all the conclusions reached in this paper can be supported on this evidence alone. Nevertheless, the first 13 estimates of plasma volume made by the extraction method do not appear to be inconsistent with the remaining data, and they have therefore been included; these observations are specially marked in the tables and figures.

Determination of Red Cell Vohne with Radioactive Phosphorus. The method used was essentially the same as that described by Reeve and Veall (1949), with only minor modifications. About $5 \mathrm{ml}$. of the infant's blood were incubated with 5 to 10 micro-curies* of $\mathrm{P}^{32}$ for 30 to 45 minutes, so that, after washing, the red cells contained about 1 micro-curie of $\mathbf{P}^{32}$. After the red cells had been washed the volume of saline suspension was

- The Poe was supplied partly by Oak Ridge National Laboratories, U.S.A.E.C., and partly by the Atomic Energy Research Establishment, Harwell, through the M.R.C. The quantities were measured in terms of the micro-curie adopted by the M.R.C. as the standard of activity for pas for the year 1949. adjusted to $5-10 \mathrm{ml}$. Of this suspension $1 \mathrm{ml}$. was injected into the infant and $1 \mathrm{ml}$. was used for the preparation of a standard 1/100 dilution. Consequently, the $P^{22}$ dose was 0.1 to 0.2 micro-curies in the form of labelled red cells.

Syringe calibration tests in vitro using a labelled red cell suspension showed that with the syringe selected for these experiments it was possible to inject $1 \mathrm{ml}$. of radioactive red cell suspension with an error of less than $1 \%$.

The blood samples were taken into dry, heparinized $10 \mathrm{ml}$. graduated centrifuge tubes. After removal of sufficient blood for haematocrit determination, the tubes were covered with a cellophane cap and centrifuged at 3,000 r.p.m. for 20 to 30 minutes. The volume of the blood sample could then be read to within $\pm 0.05 \mathrm{ml}$. The supernatant plasma was removed for dye estimation, and sufficient phosphate-citrate buffer solution was then added to the packed red cells to bring the volume of the sample to $10 \mathrm{ml}$. After lysing the red cells with saponin, the $\mathrm{P}^{\mathrm{s} 2}$ content of each sample was compared with that of the standard by means of a liquid sample counter (Veall, 1948). After correcting for dilution, haematocrit and $\mathrm{P}^{32}$ loss from the red cells in vivo, the $\mathrm{P}^{22}$ content per $\mathrm{ml}$. of red cells was obtained. The amount of $\mathrm{P}^{32}$ injected could be determined from the value of the standard solution, and thus the infant's red cell volume could be calculated. The correction for $P^{32}$ loss was the same as that used by Reeve and Veall in their work on adults, i.e. $+1 \%$ for a 10 -minute sample, $+2 \%$ for a 20-minute sample, etc. In a number of cases two or more samples were obtained from the infant, usually at 10 and 20 minutes after injection of the labelled red cells, and no significant difference was found between the figures for red cell volume calculated from these two samples. Consequently, it would appear that no appreciable error is introduced by assuming that the rate of loss of $P^{32}$ from red cells is approximately the same in infants as it is in adults.

Radiation Dosage. The question of radiation dosage received by the patient when this method is used for the determination of red cell volume is discussed in detail by Reeve and Veall (1949). In the present experiments the amount of $P^{32}$ used was less than 0.1 micro-curie per $\mathrm{kg}$. body weight. Assuming that all the injected $\mathrm{P}^{32}$ remains in the blood stream for the first 24 hours after injection, and assuming a blood volume of $85 \mathrm{ml}$./ $\mathbf{k g}$., the blood and the immediate environs of the vascular system would receive a radiation dose of 0.049 equivalent roentgens (r.) in 24 hours. This can be regarded as the absolute maximum dose received by any organ in the body in any one day, and is certainly an overestimate. The loss rate of $P^{32}$ from the blood is such that about half of it has disappeared in $\mathbf{2 4}$ hours, to be distributed around the body or excreted. This figure may be compared with that for the maximum permissible daily radiation dose of $0.1 \mathrm{r}$., which is currently accepted (M.R.C., 1949) for those who encounter radiation hazards every working day throughout their life. Alternatively, if the radio phosphorus is considered to have been redistributed and fixed uniformly all over the body, then, neglecting excretion, the tissues would receive a total dose of $0.087 \mathrm{r}$. during the radioactive life of the $\mathrm{P}^{* 2}$, spread 
over several weeks. It is known that $\mathrm{P}^{32}$ is selectively taken up by certain tissues, though probably not in excess of about six times the average body concentration. Such tissues would thus receive a total of about $0.5 \mathrm{r}$., again spread over several weeks. This appears to be of the same order as the dose received by the foetus when a single radiograph is taken during pregnancy, or the skin dosage received as a result of an ordinary diagnostic $x$-ray film (Martin, 1947). In any case, even in an organ in which the concentration was six times the average throughout the body, the maximum dose rate would be the initial one of $0.024 \mathrm{r}$. per day, which is still considerably less than the maximum permissible daily dose. Thus, the radiation hazard of this method of investigation is no greater, and is almost certainly less, than that of a single routine $x$-ray examination.

Determination of Red Cell Volume by the Astby Method. In five cases red cell volume was determined by the Ashby method as modified by Barnes, Loutit, and Reeve (1948). Some further modifications were necessary to make the method suitable for use in infants. Three of the infants tested were affected with haemolytic disease of the newborn and were transfused with $R h$ negative blood; the fourth infant was transfused because it was found to be pale and cold after birth and it was considered that it would benefit by transfusion. In each of the five cases approximately $10 \mathrm{ml}$. of the infant's blood was first removed and then an accurately measured amount $(40-50 \mathrm{ml}$.) of fresh blood of suitable group was injected from an all-glass $50 \mathrm{ml}$. syringe over a period of some 10 or 15 minutes. These manipulations were carried out through a polythene catheter passed up the umbilical vein. Five to ten minutes after the end of the injection a fresh catheter was passed and a sample of blood obtained. The concentration of donor red cells in the post-transfusion blood sample was estimated by differential agglutination using anti-A or anti-M serum. The red cell volume of the infant after transfusion was calculated from the formula given by Barnes et al. (1948). The red cell volume before transfusion was then calculated by deducting the volume of red cells injected and adding the volume of red cells removed in the first blood sample. In making the red cell counts, both on the donor blood sample and on the infant's posttransfusion samples, not less than 2,000 red cells were counted.

Venous Haematocrit. The venous haematocrit was determined by centrifuging blood samples in ordinary Wintrobe haematocrit tubes; the tubes were spun for 30 minutes at 3,000 r.p.m. in a centrifuge of $15 \mathrm{~cm}$. radius. Following Barnes et al. (1948), all observed readings were multiplied by the factor 0.95 to correct for trapped plasma and thus to give a true estimate of the volume of red cells in the sample. For the estimation of red cell volume, it was necessary to determine the height of the red cell column in the haematecrit tube, rather than the total height of the cell column. In practice this was sometimes difficult because the separation between red cells and white cells was often not so sharp as in the adult haematocrit. Often there were two layers above the red cell column, the lower of the two being pink and the upper white. The pink layer was sometimes not separated from the main red cell column by any sharp dividing line. Since the upper layer usually occupied only about 0.5 of a division, whereas the pink layer occupied one or two divisions, and the leucocyte count is known to be considerably higher in the infant than in the adult, it was considered that the subtraction of only 0.5 from the total height of the column would not give a fair estimate of the red cell volume. Moreover, direct microscopic examination showed that the pink layer was in fact a mixture of red and white cells. It was decided that the most satisfactory method of dealing with this difficulty was to subtract 2.0 from the total height of the column in all cases, whether or not the dividing lines seemed to be sharp. Thus the true volume of red cells in all venous samples was calculated from the formula (P.C.V. - 2) $\times 0.95$, packed cell volume (P.C.V.) being the total height of the cell column in the venous haematocrit. In all the tables and figures in this paper, the term 'venous haematocrit' is used for this estimate of the proportion of red cells in unit volume of venous blood.

\section{Results}

All measurements of plasma volume and red cell volume are recorded in Table 1, together with various deductions from the data. The cases are arranged in order of venous haematocrit.

Plasma Volume. In Fig. 1 estimations of plasma volume, expressed in ml./kg., have been plotted against venous haematocrit. The cases appear to fall into two groups.

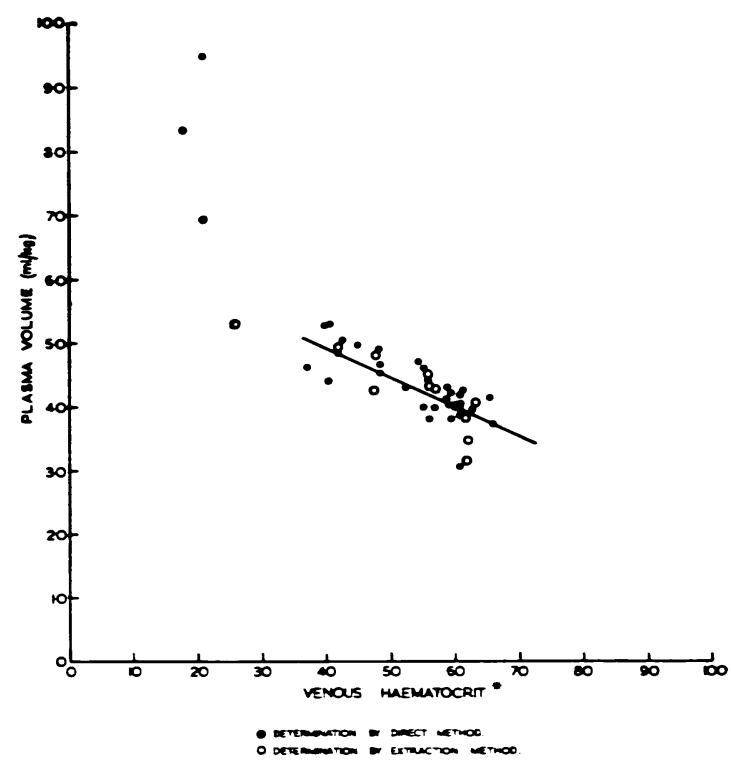

FIG. 1.*-Estimates of plasma volume in 46 newborn infants. plotted against venous haematocrit. The regression line has been calculated from data relating to the 34 normal infants; the slope of the line $=-0.454$ $\doteq \mathbf{0 . 0 0 8}$. 
(1) Almost all the observations fall in the haematocrit range $37-66 \cdot 2$, and in this range there is a slight but steady fall in plasma volume as haematocrit rises. The regression line drawn in Fig. 1 has been calculated from data applying to 34 normal infants only, and it will be noted that the slope of the line is some $\mathbf{5 0}$ times its standard deviation. If the $\mathbf{3 4}$ normal infants are divided into two groups, those with a venous haematocrit of $59 \cdot 3-66 \cdot 2$ are found to have an average plasma volume of $38.6 \mathrm{ml} . / \mathrm{kg}$. (standard error of mean $=0.81$ ), and those with haematocrits ranging from $39 \cdot 9-58 \cdot 5$ have an average plasma volume of $44 \cdot 1 \mathrm{ml}$. $/ \mathrm{kg}$. (S.E. of mean $=0 \cdot 88$ ).

(2) The four most anaemic infants (haematocrit range $17 \cdot 9-21 \cdot 2$ ) had much greater plasma volumes; all four infants were found to have an increased venous pressure and were considered to be in cardiac failure (Mollison and Cutbush, 1949).

The time after birth at which plasma volume was estimated did not appear to affect the results significantly. The estimates made within three hours, and even within two hours, were distributed about the regression line in the same way as the estimates made later after birth.

Red Cell Volume. In Fig. 2 observed red cell volume in $\mathrm{ml} . / \mathrm{kg}$. is plotted against venous haematocrit. It appears that the relationship is substantially linear up to a certain haematocrit levelapproximately 55-but that above that level the

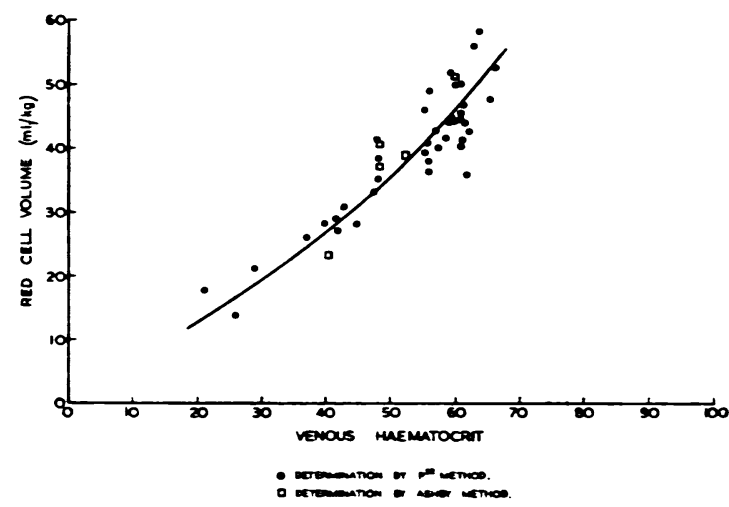

FiG. 2.*-Estimates of red cell volume (ml. kg.) in 43 newborn infants plotted against venous haematocrit. The line is not a calculated regression line but merely indicates the trend of the data. venous haematocrit does not accurately reflect the true red cell volume.

Total Blood Volume. Total blood volume was calculated by adding together observed red cell

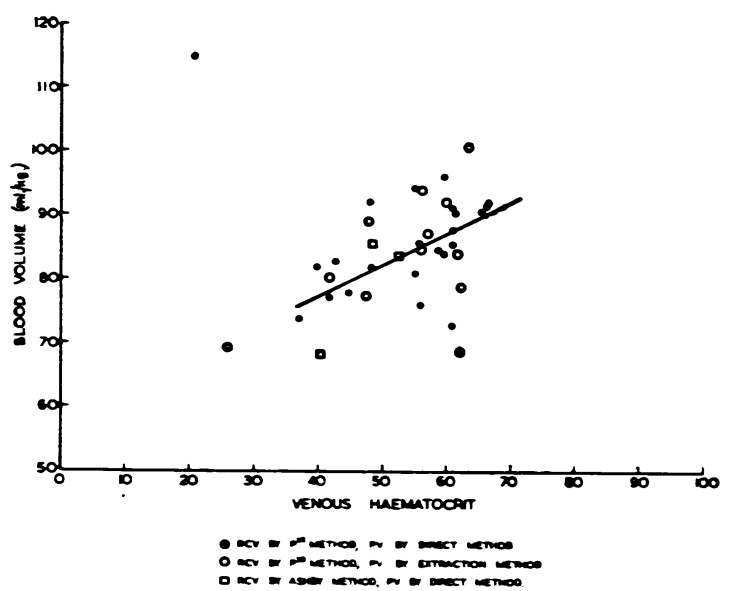

Fig. 3.*-Estimates of total blood volume (ml./kg.) based on separate estimates of plasma volume and red cell volume in 37 newborn infants, plotted against venous haematocrit. The regression line has been calculated from data relating to the 28 normal infants; the slope of the line $=0.4791 \pm 0.3841$ (not significant):

volume and plasma volume and multiplying the total by the factor $1 \cdot 02$. This correction had to be applied to take into account the volume of leucocytes in the circulation. It will be remembered that, throughout, red cell volume was estimated from the formula (P.C.V. - 2) $\times$ 0.95. All estimates for total blood volume in $\mathrm{ml} . / \mathrm{kg}$. are plotted against venous haematocrit in Fig. 3.

One infant had a much higher blood volume than any of the others. This was one of the four infants in cardiac failure, mentioned above; in the other three of these infants either the red cell volume or the infant's weight was not known so that comparisons were impossible. The remaining cases show a tendency for blood volume to increase as venous haematocrit rises; however, the slope of the regression line in this series is not quite significant (only $1 \frac{1}{2} \times$ S.D.).

Twenty-eight of the infants whose total blood volume was estimated were normal. (Cases of haemolytic disease, however mild, are excluded from this group.) The average blood volume of these infants was found to be $84.7 \mathrm{ml} / \mathrm{kg}$. Since the majority of these cases had haematocrits above the range for normal adults (average of the group $=56 \cdot 8$ ), it was considered interesting to select infants whose venous haematocrit fell within the adult range and to compare red cell volume and 


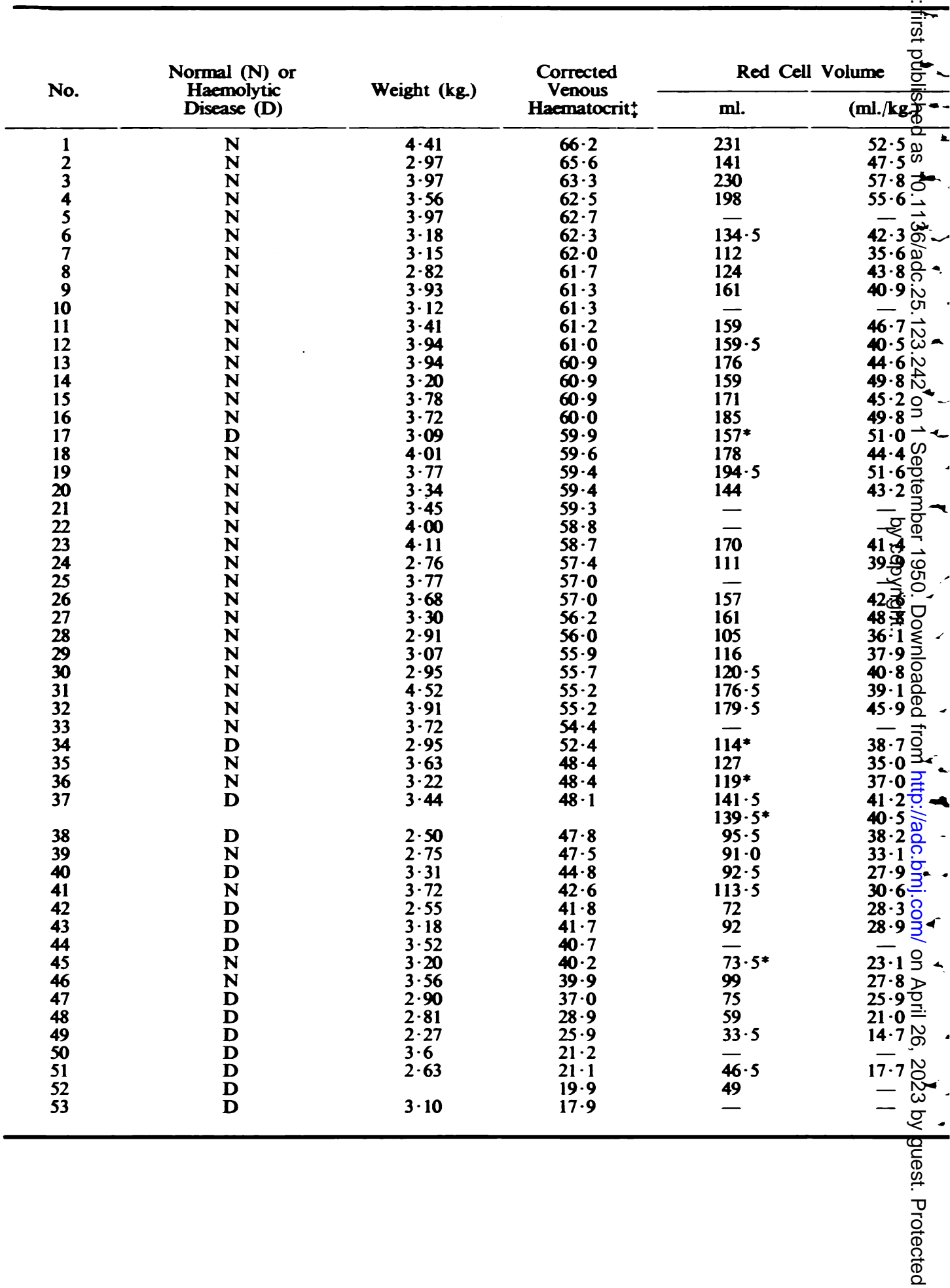


plasma volume in such infants with published figures for adults. For comparison with the figures of Reeve and Veall, which refer to 13 adults with

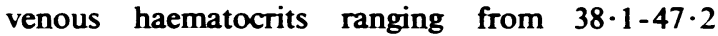
(average haematocrit 42.5), nine infants with haematocrits ranging from 37.0 to $47 \cdot 5$ (average 42.6) were selected; five of these infants had haemolytic disease of the newborn, but none appeared to have any disturbance of the circulation. In Table 2 the results of these estimations are set out, together with figures calculated from the published data of Reeve and Veall (1949) and Gibson et al. (1946).

It will be noted that for a comparable level of venous haematocrit, red cell volume and plasma bear the same relationship to body weight in infants as they do in adults.

Body Haematocrit. 'Whole body haematocrit' was calculated by dividing observed red cell volume by calculated total blood volume, determined as described above. This value was divided by the venous haematocrit, that is (P.C.V. -2) 0.95 , to obtain the ratio

$$
\frac{\text { body haematocrit }}{\text { venous haematocrit }}
$$

and this ratio is to be found in column 11 of Table 1. In Fig. 4 body haematocrit is plotted against venous haematocrit, and it is evident that this relationship is a constant over the haematocrit range $17 \cdot 9-66 \cdot 2$. Moreover, the extrapolated line passes through the origin. The value of the constant in this series was 0.868 . This figure is the average for 38 cases, and analysis showed that the value

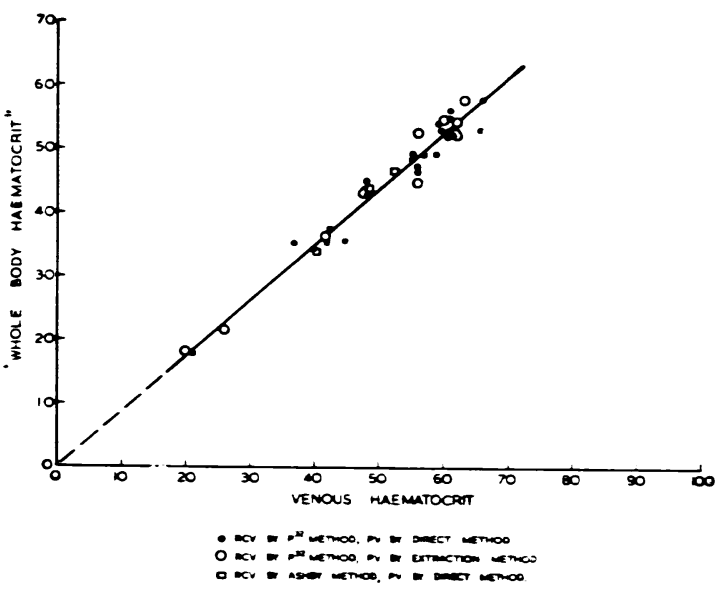

FIG. 4.*-. Whole body haematocrit' plotted against venous haematocrit in $\mathbf{3 8}$ newborn infants. was not significantly affected by the method of determining plasma volume. The detailed results were as follows:

\begin{tabular}{|c|c|c|c|}
\hline \multirow{2}{*}{$\begin{array}{c}\text { No. of } \\
\text { Cases }\end{array}$} & \multicolumn{2}{|c|}{ Method of Estimating } & \multirow{2}{*}{$\begin{array}{l}\text { Average } \\
\text { Value of } \\
\text { Constant }\end{array}$} \\
\hline & $\begin{array}{l}\text { Plasma } \\
\text { Volume }\end{array}$ & $\begin{array}{l}\text { Red Cell } \\
\text { Volume }\end{array}$ & \\
\hline $\begin{array}{r}22 \\
13 \\
3\end{array}$ & $\begin{array}{l}\text { Direct } \\
\text { Extraction } \\
\text { Direct }\end{array}$ & $\begin{array}{c}\text { Pez } \\
\text { Paz } \\
\text { Ashby }\end{array}$ & $\begin{array}{l}0 \cdot 863 \\
0 \cdot 872 \\
0 \cdot 876\end{array}$ \\
\hline
\end{tabular}

\section{Discussion}

The average figure for plasma volume in 34 normal infants was $41 \cdot 3 \mathrm{ml}$./kg.; this group of infants had an average weight of $3.55 \mathrm{~kg}$. and an average venous haematocrit of 56.9. These figures may be compared with those for 17 infants tested on the first day of life by DeMarsh et al. Their infants had an average weight of $3.33 \mathrm{~kg}$. and an average haematocrit of 57.0 ; there is no mention in their paper of any correction of venous haematocrit for trapped plasma, and thus it is probable that the figure of $57 \cdot 0 \times 0.95$, or $53 \cdot 7$, should be taken as the average haematocrit for purposes of comparison. Thus the infants tested by them probably had a slightly lower venous haematocrit and would have been expected to have a slightly higher plasma volume: the average plasma volume of $42 \cdot 7 \mathrm{ml}$. $/ \mathrm{kg}$. in their 17 cases is thus in good agreement with our series.

As mentioned above, the present estimates of plasma volume are based on the dye concentration in samples taken 10 minutes after injection; and the assumption has been made that dye-loss is to some extent counterbalanced by incomplete mixing. If, in fact, mixing is complete in $\mathbf{1 0}$ minutes, all the estimates of plasma volume would have to be reduced by about $3^{\circ}$. However, in view of the absence of any reliable data about the mixing time of T-1824 in the plasma of newborn infants, we have preferred not to apply any correction factor.

DeMarsh et al. divided their cases into two groups, namely those whose cords were clamped early, and those whose cords were clamped late. The latter group had an average haematocrit of $61^{\circ}$ \% compared with an average of $51^{\circ}$ o in the group deprived of the placental blood. Plasma volume averaged $43 \mathrm{ml} . / \mathrm{kg}$. (S.D. 7.4) in the first group and $42 \mathrm{ml} . / \mathrm{kg}$. (S.D. 8.8) in the second group, so that no relationship between venous

\footnotetext{
* In Figs. 1-4 the term "venous haematocrit" is used for an estimate of the true volume of red cells in unit volume of venous blood; this estimate is based on the formula: (P.C.V. -2) $\times .95$, where P.C.V. = total packed cell volume in the venous haematocrit. -2 is an average correction for leucocytes and $\times .95$ is a correction to account for trapped plasma.
} 
haematocrit and plasma volume could be demonstrated. Nevertheless our data indicate that plasma volume does fall as venous haematocrit rises; and the error of our estimates is sufficiently small to make it possible to demonstrate that this relationship is significant.

Fig. 2 shows that the relationship between red cell volume and venous haematocrit is substantially linear up to venous haematocrit values of approximately $55^{\circ}$ o, but that at higher haematocrit levels the red cell volume increases disproportionately. Hahn and Bale (1942) found a linear relationship between red cell volume and venous haematocrit, but did not test cases with haematocrits greater than $55^{\circ} \%$.

Fig. 3 suggests that blood volume rises with venous haematocrit, but this question is not settled decisively by our data, presumably because the errors of both the plasma volume estimation and haematocrit from the formula

$$
\frac{\text { Red cell volume }}{\text { (red cell volume) - (piasma volume) }}
$$

whereas in the present series the denominator was increased slightly to take the leucocytes into account. Nevertheless, in adults this correction would be a very small one, and would in any case not have reduced the figure of Gibson et al. to below 0.90.

It must be noted that our figure for this constant would be slightly too low if our estimates of plasma volume were too high. As mentioned above, it is possible that our estimates of plasma volume ought to be corrected by $-3^{\circ}$, and one can calculate that this would raise the value of the constant to $0 \cdot 886$. In view of the possible effect of other systematic errors, it cannot be considered that any difference between adults and newborn infants, with respect to the value of this constant, has been demonstrated.

Gibson et al. (1946) found that the ratio of

TABLE 2

\begin{tabular}{|c|c|c|c|c|c|}
\hline & & $\begin{array}{c}\text { Average } \\
\text { Venous } \\
\text { Haematocrit }\end{array}$ & $\begin{array}{c}\text { Red Cell } \\
\text { Volume } \\
\text { (ml. } \text { kg.) }\end{array}$ & $\begin{array}{c}\text { Plasma } \\
\text { Volume } \\
\text { (ml. kg.) }\end{array}$ & $\begin{array}{l}\text { R.C.V. } \\
\text { plus P.V. } \\
\text { (ml. kg.) }\end{array}$ \\
\hline $\begin{array}{l}\text { Reeve and Veall (1949): } \\
13 \text { adults with venous haematocrit } 38 \cdot 1-47 \cdot 2\end{array}$ & . & $42 \cdot 5^{*}$ & $30 \cdot 0$ & $46 \cdot 6$ & $76 \cdot 6$ \\
\hline $\begin{array}{l}\text { Gibson et al. (1946): } \\
40 \text { adults with venous haematocrit } 38 \cdot 5-48 \cdot 1\end{array}$ & . & $42 \cdot 4^{\dagger}$ & $29 \cdot 7$ & $47 \cdot 8$ & $77 \cdot 5$ \\
\hline $\begin{array}{l}\text { Present Series: } \\
\quad 9 \text { infants with venous haematocrit } 37 \cdot 0-47 \cdot 8\end{array}$ & . & $42 \cdot 6^{*}$ & $29 \cdot 2$ & $47 \cdot 9$ & $77 \cdot 1$ \\
\hline
\end{tabular}

red cell volume estimation are concerned. However, from the consideration that plasma volume presumably cannot fall to zero, it follows that at some point blood volume must start to increase with haematocrit. In practice it appears that blood volume increases with haematocrit throughout the range studied.

Fig. 4 shows a rather smaller scatter round the correlation line than do the other curves, and this may be due in part to the fact that the expression ' whole body haematocrit' is independent of body weight.

It will be noted that the value of the ratio 'whole body haematocrit'

is $0.87(0.868)$ in this series. This figure compares closely with that of 0.91 reported by Gibson, Peacock, Seligman and Sack (1946), in human adults and in dogs. The discrepancy between the two series may be a little smaller than it at first appears, tecause Gibson et al. calculated body (true red cell volume) to (red cell volume deduced from plasma volume and venous haematocrit) varied from 0.70 to 0.95 (average 0.845 ) in a group of normal males. They appear to have assumed that this figure is also a constant in normal subjects. Gibson, Aub, et al. (1947) have stated that red cell volume can be deduced from estimates of plasma volume and venous haematocrit as follows: total blood volume is first calculated from plasma volume and venous haematocrit. Plasma volume is now subtracted from total blood volume to give 'observed red cell volume.' This figure is now multiplied by 0.85 to give the true red cell volume. Gibson, Aub, et al. (1947) and Ross et al. (1947) have made use of this 'correction' to determine the red cell volume. However, it can easily be shown that the ratios
(1) $\frac{\text { Body haematocrit }}{\text { Venous haematocrit }}$
and
(2)
(True red cell volume)
$\overline{(R e d ~ c e l l ~ v o l u m e ~ d e d u c e d ~ f r o m ~ p l a s m a ~ v o l u m e ~}$ 
cannot both be constants, when red cell volume is deduced in this way. A simple concrete example is perhaps the clearest way of illustrating this point:

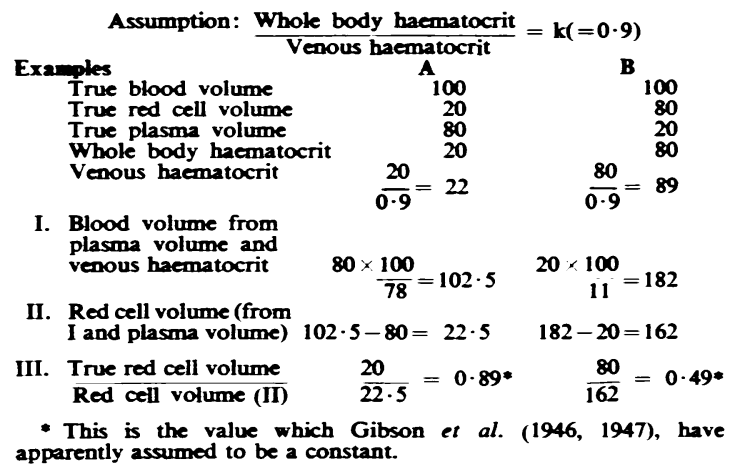

Evidently the error in assuming that the ratio of true red cell volume to 'deduced red cell volume is a constant will be much less serious over a narrow range of haematocrit values than in the extreme examples used above.

Calculation of Blood and Red Cell Volume from Plasma Volume and Body Haematocrit. If the total blood volume is to be calculated from estimates of plasma volume and venous haematocrit it may be calculated as follows.

The observed packed cell volume (that is, total height of red cells plus white cells in the venous haematocrit) is first corrected by the factor 0.95 to allow for plasma trapped in the cell column, and this figure is then multiplied by $0 \cdot 87^{*}$ to obtain the true proportion of cells present in unit volume of blood in the body as a whole. The true proportion of plasma in the blood is then obtained by subtracting this figure from 100; this proportion may be expressed briefly as the 'body plasmatocrit.'

$$
\begin{aligned}
& \text { i.e. body plasmatocrit }=100-0 \cdot 87(P . C . V . \times 0.95) \\
& \text { when P.C.V. =total height of cell column in } \\
& \text { the venous haematocrit } \\
& \text { Then Blood Volume }=\frac{\text { Plasma volume }}{\text { Body plasmatocrit }} \times 100 \\
& \text { Similarly, red cell volume } \\
& =\text { Plasma volume } \times \text { body red cell haematocrit } \\
& \text { Body plasmatocrit }
\end{aligned}
$$

In the last two columns of Table 1 are to be found, first, red cell volume calculated from plasma volume and haematocrit, using the above formula, and second the 'error' of the estimation; that is to say, the percentage deviation from estimations of

- This figure for the constant is valid for plasma volume estimates in newborn infants based on the dye concentration in a 10-minute sampte, uncorrected for possible errors due to incomplete mixing or loss of dye. If further work should show that the true plasma volume is bome plasmatocrit' would become $100-.886$ (P.C.V. $\times 0.95$ ), or $100-($ P.C.V. $\times 0 \cdot 84)$. red cell volume made with labelled red cells. The coefficient of variation of the calculated red cell volumes was found to be $8 \cdot 8^{\circ}{ }_{\circ}$; it is to be noted that this 'error' includes the error of estimating red cell volume with labelled red cells, as well as the error of estimating plasma volume. Moreover, it takes no account of biological variation.

Assuming that the experimental errors of measuring plasma volume and red cell volume are similar, the error of deducing red cell volume from plasma volume and venous haematocrit using the above formula, becomes $\frac{8 \cdot 8}{\sqrt{2}}=$ approximately $\pm 6^{\circ} \%$.

\section{Summary}

Estimations of plasma volume (using T-1824) or red cell volume (using labelled red cells) have been made in 53 newborn infants, of which 38 were normal and 15 affected with haemolytic disease of the newborn. In 38 infants both plasma volume and red cell volume were estimated.

In 34 normal infants the average plasma volume was $41 \cdot 3 \mathrm{ml}$./kg. However, plasma volume was not independent of haematocrit but on the contrary rose steadily throughout the venous haematocrit range $66 \cdot 2-37 \cdot 0$. In four infants with haematocrits between $17 \cdot 9$ and $21 \cdot 2$, plasma volume was disproportionately raised, but these infants were in cardiac failure.

Red cell volume was measured in 44 infants. The relationship between venous haematocrit and red cell volume was approximately linear when the venous haematocrit was below $55^{\circ}$. However, above this level the venous haematocrit did not rise proportionately to the true red cell volume.

The total blood volume of 28 normal newborn infants, deduced from measurements of plasma volume and red cell volume, was $84.7 \mathrm{ml} . / \mathrm{kg}$. On theoretical grounds blood volume is expected to increase with venous haematocrit, but this relationship could not be demonstrated conclusively in the present cases.

The ratio of the 'whole body haematocrit,' that is

$$
\frac{\text { total red cell volume }}{\text { total blood volume }}
$$

to the venous haematocrit was found to be a constant in the venous haematocrit range $17 \cdot 9^{\circ}{ }_{o}-66 \cdot 2^{\circ}{ }_{0}$. The value of the constant in this series was 0.87 .

Provided that the venous haematocrit is first multiplied by this constant, estimates of red cll volume obtained by the dye-haematocrit method agree satisfactorily with estimates made by labelled red cell methods. 
The work described in this paper was carried out in the Institute of Obstetrics and Gynaecology and the Institute of Child Health at the Postgraduate Medical School of London. We should like to thank Professor James Young and Professor A. A. Moncrieff for facilities, and members of their staffs for help of many kinds.

\section{REFERENCES}

Barnes, D. W. H., Loutit, J. F., and Reeve, E. B. (1948). Clin. Sci., 7, 135.

Brines, J. K., Gibson, J. G., and Kunkel, P. (1941). J. Pediat., 18, 447.

DeMarsh, Q. B., Windle, W. F., and Alt, H. L. (1942). Amer. J. Dis. Child., 63, 1123.

Freis, E. D., Stanton, J. R, and Emerson, C. P. (1949). Amer. J. Physiol., 157, 153.

Gibson, J. G., Aub, J. C., Evans, R. D., Peacock, W. C., Irvine, J. W., and Sack, T. (1947). J. clin. Invest., 26, 704.

- , Peacock, W. C., Seligman, A. M., and Sack, T. (1946). J. clin. Invest., 25, 838.

Hahn, P. F., Balfour, W. M., Ross, J. F., Bale, W. F., and Whipple, G. H. (1941). Science, 93, 87.

-, and Bale, W. F. (1942). Amer. J. Physiol., 136, 314.
Hecht, H., and Greenberg, R. (1948). Personal Communication.

Lucas, W. P., and Dearing, B. F. (1921). Amer. J. Dis. Child., 21, 96.

Martin, J. H. (1947). Brit. J. Radioi., 20, 279.

Medical Research Council (1949). Introductory Manual on the Control of Health Hazards from Radioactive Materials. London.

Mollison, P. L., and Cutbush, Marie (1949). Brit. med. $J ., 1,123$.

Morris, C. J. O. R. (1944). Biochem. J., 38, 203.

Noble, R. P., and Gregersen, M. I. (1946). J. clin. Invest., 25, 158.

Reeve, E. B., and Veall, N. (1949). J. Physiol., 108, 12.

Robinow, M., and Hamilton, W. F. (1940). Amer. J. Dis. Child., 60, 827.

Ross, J. F., Finch, C. A., Peacock, W. C., and Sammons, M. E. (1947). J. clin. Invest., 26, 687.

Russell, S. J. M. (1949). Arch. Dis. Childh., 24, 88.

Schücking, A. (1879). Berl. klin. Schnschr., 16, 581.

Smith, H. P., Arnold, H. R., and Whipple, G. H. (1921). Amer. J. Physiol., 56, 336.

Veall, N. (1948). Brit. J. Radiol., 21, 347. 